\title{
Risk Assessment and Regionalization of Rainstorm - Flood Disasters in Shanxi
}

\author{
Huaming Zhang ${ }^{1}$, Yaolong Liu ${ }^{2}$, Jianxin Zhang ${ }^{1}$, Lin Wang ${ }^{1}$ \\ ${ }^{1}$ Meteorological disaster prevention technology center of Shanxi province, Taiyuan 030002, China \\ ${ }^{2}$ College of Economics and Management, Taiyuan University of Technology, Jinzhong 030600, \\ China
}

\section{山西省暴雨洪港灾害危险性评估与区划 \\ 张华明 ${ }^{1}$, 刘耀龙 ${ }^{2}$, 张建新 ${ }^{1}$, 王林 ${ }^{1}$ \\ ${ }^{1}$ 山西省气象灾害防御技术中心, 太原 030002, 中国 \\ ${ }^{2}$ 太原理工大学经济管理学院, 晋中 030600 , 中国}

\begin{abstract}
Rainstorm- flood are one of the main meteorological disasters in Shanxi province, resulting in a large number of casualties, assets damage and economic losses. Based on the historical disaster data of rainstorm- flood, and considering the two aspects of disaster frequency and disaster impact, the hazard index model and classification standard of rainstorm- flood are constructed. The risk level of rainstorm- flood disaster in each county (district) of Shanxi is evaluated. Combined with the meteorological geographical regionalization of Shanxi, the plan of hazard zoning for rainstorm- flood disaster in Shanxi is put forward, which provides decisionmaking reference for regional disaster prevention and reduction.
\end{abstract}

Keywords: rainstorm- flood; hazard; assessment; Shanxi province

\section{摘要}

暴雨洪涝是山西省主要气象灾害之 一，造成大量的人员伤亡、资产破坏和经 济损失。本文基于暴雨洪涝历史灾情数

E-mail: zhanghuaming980@163.com.
据, 综合考虑灾害频率和灾害影响两个方 面, 构建暴雨洪涝灾害危险性指数模型与 分级标准, 评估山西各个县 (区) 暴雨洪 涝灾害危险性水平。结合山西气象地理区 划, 提出山西省暴雨洪涝灾害危险性区划 方案, 为区域防灾减灾提供决策参考。

关键词: 暴雨洪涝; 危险性; 评估; 山西 省

1. 引言

广布型灾害风险（Extensive Disaster Risk）的辨识与评估是近年来国际社会和学 术界关注的热点问题之一 [1]。据联合国国 际减灾战略（简称 UNISDR）统计, 96\%的 广布型灾害是“与天气有关的灾害”[2], 其 中 $40.91 \%$ 的灾情报告与洪水、山洪、城市 内涝和暴雨有关。暴雨洪涝是山西省主要 的气象灾害之一。1983-2015 年期间, 有记 录的暴雨洪涝灾害多达 660 条, 占各类灾害 记录的 $13.80 \%$; 累计受灾人口 689.13 万 人, 累计损坏房屋 42.82 万间, 累计直接经 济损失 10080.43 亿元, 农作物累计受灾面 积 140.98 万公顷, 公路累计损坏 9512.59 公 里。山西省暴雨洪涝灾害广泛分布于山西 省 11 个地市及大多数区县, 其危险性和潜 在风险极大。本文考虑灾害发生频率和灾 害造成影响两个方面, 通过构建暴雨洪涝 灾害危险性评估模型, 开展山西省暴雨洪 
涝灾害危险性评估与区划, 为区域有效管 控风险和防灾减灾决策提供参考。

\section{2. 数据来源与评估方法}

暴雨洪涝灾害历史灾情记录来源于各 类文献记载和部门记录, 涉及到的数据源 或业务部门有: 国家自然灾害灾情管理系 统、《地面气象记录年报表》、《气象年 鉴》、《灾情快讯》、《县/市志》、《县/市年 鉴》、省或县（市）民政局、政府办、气象 局、水利/水务局、农业局、档案局、乡 (镇) 政府, 保险公司等。经统计, 19832015 年山西省暴雨洪涝历史灾情有效记录 共计 660 条, 记录内容包括发生时间、地点 (县或区)、气象要素实况 (如降雨量、洪 涝水深、风速等) 和主要灾害影响 (如受 灾人口、死亡人口、受伤人口、倒塌房 屋、损坏房屋、直接经济损失、农作物受 灾面积、公路损坏长度等)。

参考国家标准《暴雨灾害等级 GBT33680-2017》中暴雨等级的计算方法 [3], 暴雨洪涝灾害危险性评估主要考虑灾 害频率和灾害影响两个方面, 量化指标为 暴雨洪涝灾害危险性指数 HIr, 其计算方法 为:

$H I_{r}=0.5 \times R F+0.5 \times(R C+R H+R E+R A+R R) / 5$

式中, $R F$ 为年均暴雨洪涝灾害指标等级; $R C$ 为次均人员伤亡指标等级, $R H$ 为次均 房屋损坏指标等级, $R E$ 为次均直接经济损 失指标等级, $R A$ 为次均农作物受灾面积指 标等级, $R R$ 为次均公路损失指标等级。采 用标准差分类方法, 将 $H I_{r}$ 划分为四个等 级, 见表 1 。

表 1 暴雨洪涝灾害危险性指数等级划分

\begin{tabular}{ccccc}
\hline 危险等级 & 轻度 & 中度 & 严重 & 特大 \\
\hline$H I_{r}$ & $H I_{r}<1.66$ & $1.66 \leqslant H_{r}<2.18$ & $2.18 \leqslant H I_{r}<2.70$ & $H I_{r} \geqslant 2.70$ \\
\hline
\end{tabular}

$R F$ 通过年均暴雨洪涝灾害指标 $F_{r}$ 加以 确定 (表 2), $F_{r}$ 的计算方法为:

$$
F_{r}=\sum_{i}^{j} N_{i} / N
$$

式中, $N_{i}$ 为第 $i$ 年暴雨洪涝灾害数, 单位为 次; $i$ 为年份, $N$ 为总年数。
表 2 年均暴雨洪涝灾害指标等级划分

\begin{tabular}{ccccc}
\hline 等级 $(R F)$ & 1 & 2 & 3 & 4 \\
\hline$F_{r}$ & $0 \leqslant F_{r}<0.11$ & $0.11 \leqslant F_{r}<0.46$ & $0.46 \leqslant F_{r}<0.62$ & $F_{r} \geqslant 0.62$ \\
\hline
\end{tabular}

$R C$ 通过次均人员伤亡指标 $C_{r}$ 加以确定 (表 3), $C_{r}$ 的计算方法为:

$$
C_{r}=\sum_{i}^{j} N C_{i} / \sum_{i}^{j} N_{i}
$$

式中, $N C_{i}$ 第 $i$ 年暴雨洪涝灾害导致的 死亡和受损人数, 单位为人; 其它同上。

表 3 次均人员伤亡指标等级划分

\begin{tabular}{ccccc}
\hline 等级 $(R C)$ & 1 & 2 & 3 & 4 \\
\hline$C_{r}$ & $0 \leqslant C_{r}<1$ & $1 \leqslant C_{r}<3$ & $3 \leqslant C_{r}<5$ & $C_{r} \geqslant 5$ \\
\hline
\end{tabular}

$R H$ 通过次均房屋损坏指标 $H_{r}$ 加以确定 (表 4), $H_{r}$ 的计算方法为:

$$
H_{r}=\sum_{i}^{j} N H_{i} / \sum_{i}^{j} N_{i}
$$

式中, $N H_{i}$ 第 $i$ 年暴雨洪涝灾害导致的 房屋毁坏和受损数, 单位为间; 其它同 上。

表 4 次均房屋损坏指标等级划分

\begin{tabular}{ccccc}
\hline 等级 $(R H)$ & 1 & 2 & 3 & 4 \\
\hline$H_{r}$ & $0 \leqslant H_{r}<212$ & $212 \leqslant H_{r}<900$ & $900 \leqslant H_{r}<1587$ & $H_{r} \geqslant 1587$ \\
\hline
\end{tabular}

$R E$ 通过次均直接经济损失指标 $E_{r}$ 加以 确定 (表 5), $E_{r}$ 的计算方法为:

$$
E_{r}=\sum_{i}^{j} N E_{i} / \sum_{i}^{j} N_{i}
$$

式中, $N E_{i}$ 为第 $i$ 年暴雨洪涝灾害导致 的直接经济损失, 单位为万元; 其它同 上。

表 5 次均直接经济损失指标等级划分

\begin{tabular}{ccccc}
\hline \multicolumn{1}{c}{ 等级 $(R E)$} & 1 & 2 & 3 & 4 \\
\hline$E_{r}$ & $0 \leqslant E_{r}<95.42$ & $955.42 \leqslant E_{r}<2732.25$ & $2732.25 \leqslant E_{r}<4509.07$ & $E_{l} \geqslant 4509.07$ \\
\hline
\end{tabular}

$R A$ 通过次均农作物受灾面积指标 $A_{r}$ 加 以确定 (表 6), $A_{r}$ 的计算方法为:

$$
A_{r}=\sum_{i}^{j} N A_{i} / \sum_{i}^{j} N_{i}
$$

式中, $N A_{i}$ 为第 $i$ 年暴雨洪涝灾害导致 的农作物受灾面积, 单位公顷; 其它同 上。

表 6 次均农作物受灾面积指标等级划分

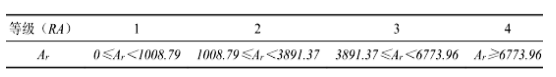

$R R$ 通过次均公路损失指标 $R r$ 加以确定 
(表 7), $R r$ 的计算方法为:

$$
R_{r}=\sum_{i}^{j} N R_{i} / \sum_{i}^{j} N_{i}
$$

式中, $N R_{i}$ 为第 $i$ 年暴雨洪港灾害导致 的公路损坏长度, 单位为千米; 其它同 上。

表 7 次均公路损坏指标等级划分

\begin{tabular}{ccccc}
\hline 等级 $(R R)$ & 1 & 2 & 3 & 4 \\
\hline$R_{r}$ & $0 \leqslant R_{r}<11.32$ & $11.32 \leqslant R_{r}<61.21$ & $61.21 \leqslant R_{r}<102.43$ & $R_{r} \geqslant 102.43$ \\
\hline
\end{tabular}

\section{3. 评估结果与区划方案}

\section{1 危险性等级}

在有暴雨洪涝灾害记录的 96 个县 (区) 中, HIr 最大值为 3.10 (晋城市陵 川县), 最小值为 1.00 (13 个县/区), 平 均值为 1.67 (中度危险性)。属于特大危险 性的县/区有: 晋城陵川、忻州保德、晋城 泽州、阳泉孟县、临汾安泽、长治平顺和 晋城阳城; 严重危险性的县/区有: 大同市 辖区、灵丘和阳高、吕梁临县、阳泉市辖 区、晋中左权、长治黎城和襄垣、晋城高 平、运城平陆; 其他县/区属于中度和轻度 危险区。

灾害频数方面, 晋城泽州和阳城年均 暴雨洪涝灾害超过 0.91 次; 人员伤亡方 面, 阳泉市辖区每次暴雨洪涝灾害致人死 伤 76 人, 忻州保德每次暴雨洪涝灾害致人 死伤 56。房屋毁坏方面, 晋中左权每次暴 雨洪涝灾害损坏房屋 20544 间, 阳泉市辖 区每次暴雨洪涝灾害损坏房屋 8438 间; 直 接经济损失方面, 吕梁离石区暴雨洪涝导

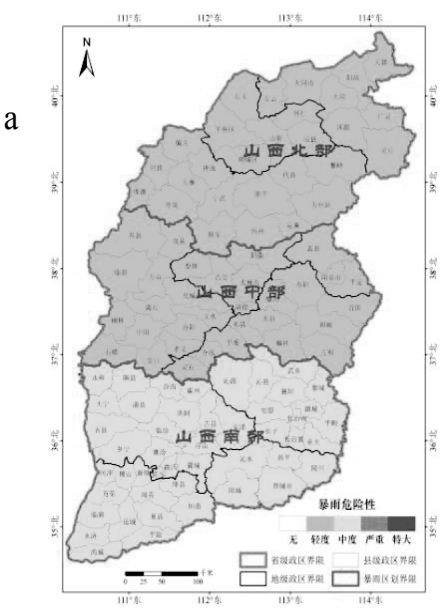

致的次均直接经济损失大 5000 多亿元, 次 均直接经济损失超过 1 亿元的县/区还有阳 泉市辖区、吕梁柳林和运城稷山。农作物 受灾方面, 阳泉市辖区暴雨洪涝灾害次均 农作物受灾面积达 31044 公顷, 晋中昔阳、 运城盐湖区和忻州神池次均农作物受灾面 积均超过 10000 公顷。损坏公路方面, 吕梁 柳林每次暴雨洪涝灾害破坏公路约 256 公 里, 临汾乡宁每次暴雨洪涝灾害破坏公路 约 240 公里。

从地级市的平均水平来看, 晋城市的 HIr 最大, 为 2.4 (严重危险性), 属于中度 危险性的地市有: 长治市、大同市、阳泉 市和忻州市, 其他地市为轻度危险性水 平。其他指标方面, 晋城市的灾害频数最 高, 年均 0.6 次; 阳泉市暴雨洪涝灾害造成 的人员伤亡最多, 次均 15 人, 忻州市次 之, 次均 8 人; 吕梁市暴雨洪涝灾害直接经 济损失最严重, 次均 417 亿元; 次均农作物 受灾面积最大的是阳泉市, 为 6023 公顷/ 次; 次均公路损坏超过 20 公里的地市有: 临汾、忻州、阳泉、吕梁和晋城。

\section{2 危险性区划}

参考山西气象地理区划[4], 结合 $\mathrm{HIr}$ 评估等级, 提出山西省暴雨洪涝灾害危险 性划四级区划方案, 具体为:

(1) 一级区划: 一级区划分为两类, 按南北方位划分为北部轻度危险区、中部 轻度危险区和南部中度危险区（图 1-a),

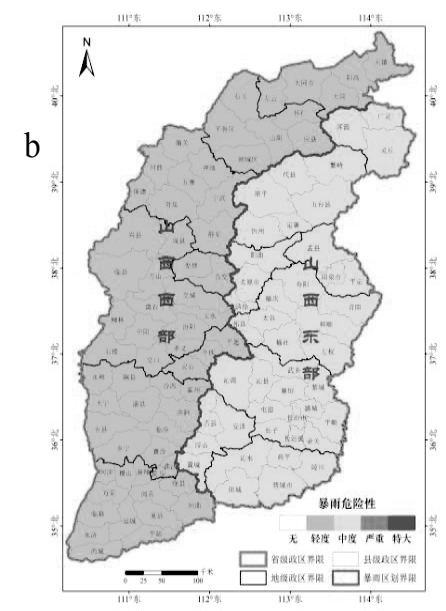

图 1 暴雨洪涝危险性一级区划 
按东西方位划分为西部轻度危险区和东部 中度危险区 (图 1-b)。

(2) 二级区划: 二级暴雨危险性区划 在一级区划的基础上, 分为 6 个区, 分别 为: 西北部中度危险区、东北部轻度危险 区、中西部轻度危险区、中东部轻度危险 区、西南部轻度危险区和东南部严重危险 区 (图 2)。

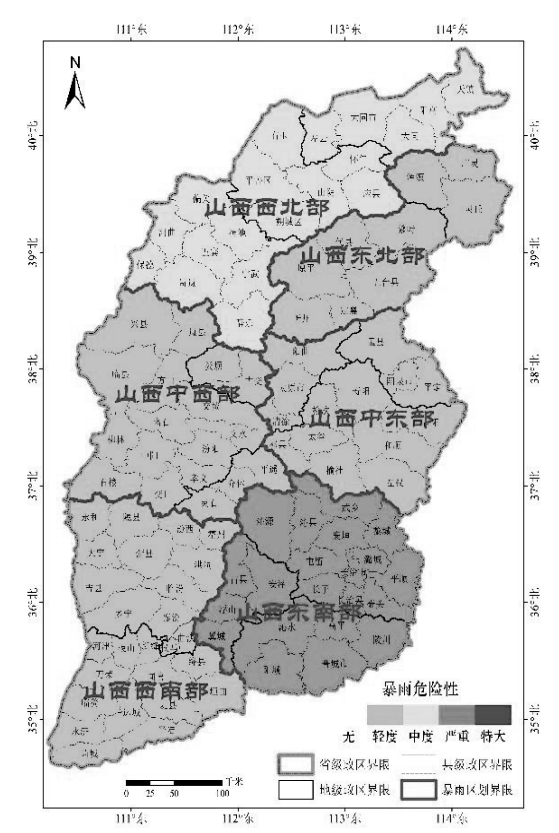

图 2 暴雨洪涝危险性二级区划

（3）三级区划: 三级暴雨危险性区划 以地级市划分, 分别为: 大同中度危险 区、朔州轻度危险区、忻州轻度危险区、 吕梁轻度危险区、太原轻度危险区、阳泉 中度危险区、晋中轻度危险区、临汾轻度 危险区、运城轻度危险区、长治中度危险 区、晋城严重危险区（图 3)。

（4）四级区划: 四级暴雨危险性区划 为各市辖区范围内的县 (区) 危险性区 划, 分别按照无危险区、轻度危险区、中 度危险区、严重危险区和特大危险区进行 划分。以晋城市为例, 特大危险区为陵 川, 严重危险区包括高平和阳城, 中度危 险区为沁水, 轻度危险区为晋城市, 不存 在无危险区（图 4)。

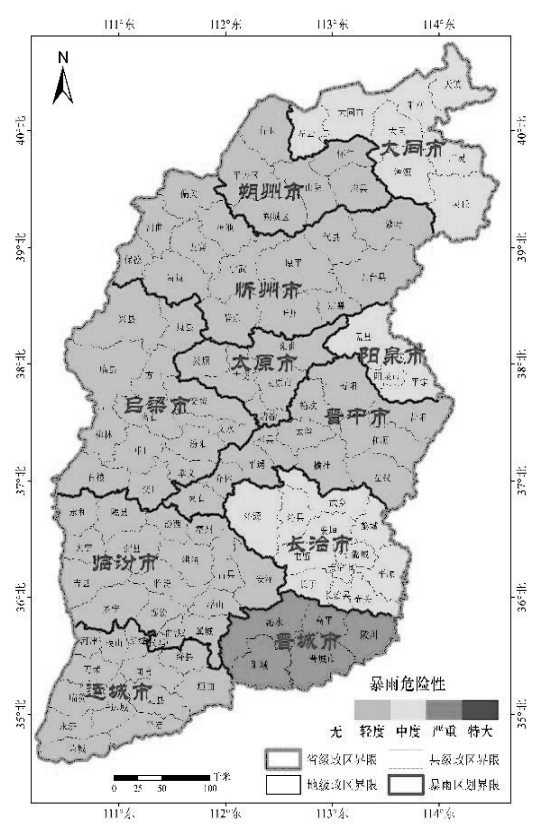

图 3 暴雨洪涝危险性三级区划图

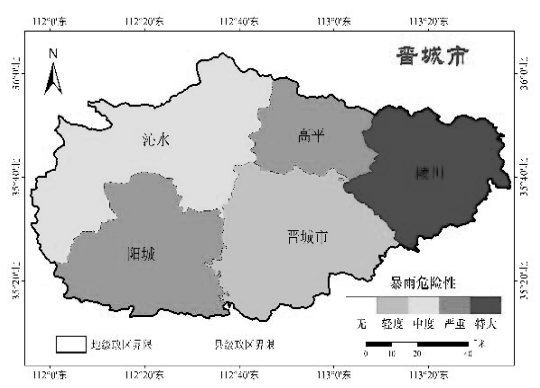

图 4 暴雨洪涝危险性四级区划 (晋中市)

\section{4. 结论与讨论}

暴雨洪涝灾害危险性评估是灾害风险 分析的重要环节, 是辨识和评价致灾因子 危险性的关键步骤。通过考量灾害频率和 灾害影响两个方面, 以灾害频数、人员伤 亡、房屋损坏、直接经济损失、农作物受 灾面积和公路损坏长度等 6 个指标的计算与 分级, 定量评估暴雨洪涝灾害的危险性指 数。研究表明:

（1）山西省平均的暴雨洪涝灾害危险 性指数为 1.65 , 属于轻度危险性水平。其 中, 晋城市严重危险性水平, 长治市、大 同市、阳泉市和忻州市属于中度危险性水 平。具体到县/区中, 晋城陵川、忻州保 德、晋城泽州、阳泉孟县、临汾安泽、长 
治平顺和晋城阳城属于特大危险性水平。

（2）山西省暴雨洪涝灾害危险性区划 分为四级。其中, 一级区划分为两类, 二 级区划分为 3 级 6 个区, 三级区划分为 4 级 11 个区, 四级区划分为 5 级若干个区。区 划方案有利于辨识区域灾害危险性特征和 风险水平, 有助于防灾减灾策略的实施。

（3）微观尺度历史灾情数据库是广布 型灾害风险分析的关键。广布型灾害风险 是指严重程度低、频率高的危害事件和灾 害的风险[5], 广泛分布且高度集中于经常 发生局部性洪水、山体滑坡、风暴或干早 的社区, 是阻碍减轻灾害风险绩效的重要 因素[6]。本文中的暴雨危险性仅表达出部 分暴雨风险, 然而对于暴雨灾害记录的要 求颇为严格。为进一步评估诸如暴雨、洪 涝等各类广布型灾害风险, 微观尺度的历 史灾情数据的搜集和整理必将成为关键。

\section{Acknowledgements}

This work was financially supported by Shanxi provincial local standard project (No. 201803).

\section{致谢}

本研究得到山西省地方标准项目 （201803）的资助。

\section{参考文献}

[1] UNISDR. 2015. Making Development Sustainable: The Future of Disaster Risk Management. Global Assessment Report on Disaster Risk Reduction (GAR 2015). http://www.preventionweb.net/english/hy ogo/gar/2015/en/home/index.html.

[2] UNISDR. 2009. Risk and poverty in a changing climate. Global Assessment Report on Disaster Risk Reduction (GAR 2009).

http://www.preventionweb.net/english/hy ogo/gar/2009/?pid:34\&pif:3.

[3] 中华人民共和国质量监督检验检疫总 局,中华人民共和国标准化管理委员会. 中华人民共和国国家标准:暴雨灾害等 级(GBT33680-2017) .2017.
[4] 山西省质量技术监督局. 山西省地方标 准: 山西气象地理区划(DB14T 7022012).2012.

[5] United Nations. 2016. Report of the open-ended intergovernmental expert working group on indicators and terminology relating to disaster risk reduction (A/71/644) . http://www.preven tionweb.net/files/50683_oiewgreportengli sh.pdf.

[6] Xue Y, Li X X, Su W, et al. 2018. A fuzzy method for assessing eco-environmental disaster risk caused by coalbed methane in China. Journal of Risk Analysis and Crisis Response, 2018, 8 (1): 3-13. 